\title{
Bronchiolitis obliterans syndrome in popcorn production plant workers
}

\author{
M. Akpinar-Elci*, W.D. Travis", D.A. Lynch", K. Kreiss*
}

Bronchiolitis obliterans syndrome in popcorn production plant workers. M. Akpinar-Elci, W.D. Travis, D.A. Lynch, K. Kreiss. C ERS Journals Ltd 2004.

ABSTRACT: Following sentinel case recognition, an excess of fixed airways obstruction was found among current workers in a microwave popcorn plant associated with butter flavouring exposures.

In order to characterise the clinical presentation of sentinel cases, the medical records of sentinel cases were reviewed, interviews conducted and serial spirometric testing performed.

Cases worked in microwave popcorn production, and five of the nine cases had mixed flavourings. Most had never smoked or smoked minimally. Cases showed onset of cough, shortness of breath and wheezing 5 months to 9 yrs after starting work at the popcorn plant. Initial forced expiratory volume in one second ranged $14.0-66.8 \%$ of the predicted value. Eight high-resolution computed tomography scans showed marked bronchial wall thickening and mosaic attenuation with air trapping. Open lung biopsy results were consistent with, or diagnostic of, constrictive bronchiolitis in two of three cases. Five cases are on lung transplantation waiting lists. After leaving employment, nearly all cases experienced stabilisation of their lung function within $\mathbf{2}$ yrs.

Astute clinicians can help identify new causes of airways obstruction by alerting public health authorities to unexplained disease cases occurring in groups of workers. Eur Respir J 2004; 24: 298-302.
*Division of Respiratory Disease Studies, Centers for Disease Control and Prevention/ National Institute for Occupational Safety and Health, Morgantown, WV, "Armed Forces Institute of Pathology, Bethesda, MD, and Depts of Radiology, National Jewish Research and Medical Center and University of Colorado Health Sciences Center, Denver, $\mathrm{CO}$, USA.

Correspondence: M. Akpinar-Elci, NIOSH, Division of Respiratory Disease Studies, Field Studies Branch MS H-2800, 1095 Willowdale Road, Morgantown, WV 26505, USA. Fax: 13042855820

E-mail: melci@cdc.gov

Keywords: Airways obstruction, flavouring, food industry, occupation

Received: February 62003

Accepted after revision: March 32004
Bronchiolitis obliterans is a rare inflammatory disease of the small airways resulting from a variety of aetiologies. Occupational factors are typically recognised when workers develop fixed airways obstruction following acute lung injury caused by high workplace concentrations of noxious gases, including nitrogen dioxide, sulphur dioxide, phosgene, ammonia and chlorine [1]. The implicated causal exposures usually arise from chemical spills or other unanticipated circumstances, rather than in the course of routine work [2-5]. Nine cases of bronchiolitis obliterans syndrome without a history of chemical spills or high levels of acute exposure to recognised hazardous occupational agents from a popcorn production plant are reported here.

These cases came to public health attention in May 2000, without any of the cases having been attributed to occupational exposure. Rather, the time-space clustering of cases of severe airways obstruction in relatively young workers, at one small plant, suggested an occupational cause. Further investigation showed that these cases represented "the tip of the iceberg" of ongoing respiratory morbidity among current workers at the plant [6]. After publication of the report of this investigation by KREISS et al. [6], requests were received from the medical community regarding the details of the pathological and radiological clinical features and diagnosis of this problem. Since this was a newly recognised occupational health problem, the present article was prepared with clinical information that may benefit physicians faced with diagnostic and management decisions.

The popcorn production plant produces both flavoured microwave popcorn and unflavoured kernel popcorn. All cases worked in the microwave popcorn production area, which encompasses a mixing room, where flavourings and salt are mixed in soybean oil, and packaging lines, where bags are filled with kernel popcorn and the flavouring mixture. Analysis of air samples from the mixing room identified $>100$ volatile organic compounds. Diacetyl (2,3-butanedione), a ketone with butter-flavour characteristics, was the predominant compound. In comparison to office, warehouse and outside area workers, mixers experienced 800 times the mean exposure (32.3 parts per million ( $\mathrm{ppm}$ ) diacetyl) and microwave packaging workers 15 times the mean exposure (1.9 ppm diacetyl) [6].

Each case signed consent forms approved by the Human Studies Review Board of the National Institute for Occupational Safety and Health (NIOSH; Morgantown, WV, USA), released their medical records for review and agreed to their inclusion in the present publication. The clinical details of these cases are reported here in order to prompt clinicians to consider workplace exposures when patients present with airways obstruction, to document the natural history of these severe cases, and to explore radiological and pathological diagnostic challenges.

\section{Description of cases}

Of the nine cases among former workers of the popcorn production plant, three had never smoked, five were exsmokers (only case 1 quit before symptom onset) and one (case 7) continued to smoke (table 1). Their ages ranged 27-51 yrs (median 41 yrs).

The median duration of employment was 2 yrs (range 
1-17 yrs). Each of these workers first became symptomatic between 1993 and 2000, while employed by the plant, after a median of 1.5 yrs of employment (range 5 months -9 yrs). The mean duration of time between the onset of symptoms and the end of employment was 2.6 yrs. Five cases had been working in the mixing room when they became symptomatic, and the other four had worked in the microwave packaging area. Dry persistent cough was invariably the first symptom, and all cases reported dyspnoea and wheezing. Systemic symptoms, fever or night sweats, and mucous membrane irritation were present in most cases, and the mean weight loss was $8.7 \mathrm{~kg}$. Crackles were not recorded on chest examination in any cases. Only one case (case 9) reported respiratory difficulties on exposures pertinent to occupational or environmental lung disease prior to microwave popcorn company employment; he had experienced reversible chest tightening while working with glue and vinyl polyethylene, but these symptoms had shown complete remission prior to his employment in the popcorn production plant.

NIOSH conducted up to nine spirometry tests at intervals of several months between October 2000 and August 2003. Using standard reference equations [7], the results obtained from the medical records were used for recalculation of spirometric parameters as a percentage of the predicted values. The nine cases showed moderate-to-severe impairment on first pulmonary function testing (fig. 1). Forced expiratory volume in one second (FEV1) ranged $14.0-66.8 \%$ pred, forced vital capacity (FVC) $24-84 \%$ pred and FEV1/FVC $23-75 \%$. During initial testing, only case 2 showed postbronchodilator improvement, based on a criterion of a $200 \mathrm{~mL}$ and $12 \%$ increase in FEV1. Five months after leaving employment, case 1 had developed a bronchodilator response. Six of seven tested showed increased residual volume (table 2). Case 8 exhibited restrictive lung disease, as well as airways obstruction, with low residual volume and low total lung capacity. On first evaluation, the carbon monoxide diffusing capacity of the lung $(D \mathrm{~L}, \mathrm{CO})$ was normal in five of seven tested. Details from medical records regarding correction for haemoglobin and methods of assessing initial lung volumes were unavailable.

Chest radiographs were normal in five cases and showed

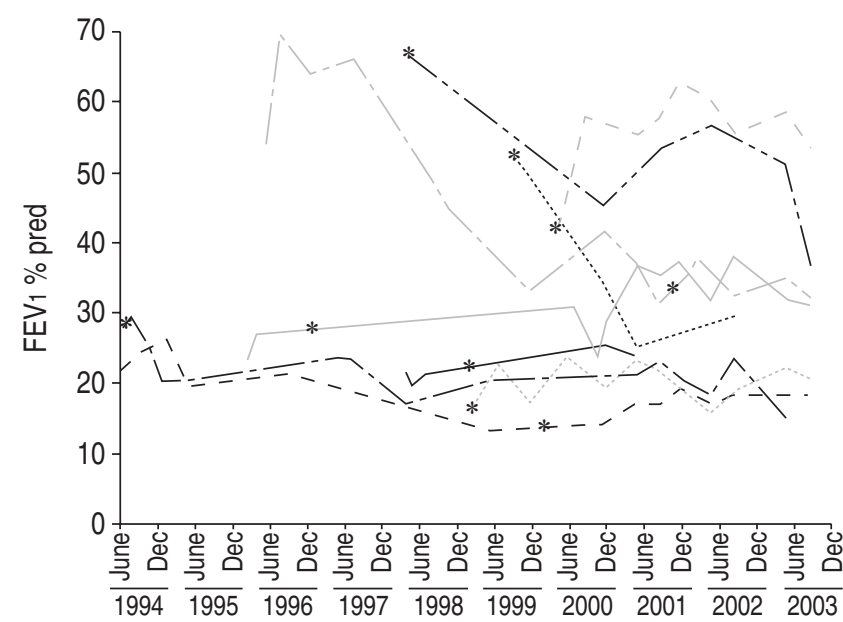

Fig. 1.-Forced expiratory volume in one second (FEV1) as a

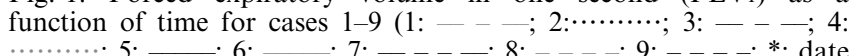
of leaving plant; characteristics and pulmonary function data are shown in tables 1 and 2). Dec: December.

hyperinflation in four. Two cases experienced pneumothorax, which was recurrent in case 9. Eight of the nine cases underwent high-resolution computed tomography (HRCT) chest scan evaluation, including expiratory computed tomography $(\mathrm{CT})$. These scans were reviewed by a thoracic radiologist, and the imaging features systematically recorded. All eight cases showed marked bronchial wall thickening and mosaic attenuation with air trapping on expiratory imaging (fig. 2). Mild cylindrical bronchiectasis was seen in cases 1, 3, 4, 5 and 9 (fig. 2). In cases 1, 3 and 9, there was mild upper lobe volume loss and subpleural nodularity suggestive of fibrosis. Case 2 showed a small amount of subpleural emphysema.

Two cases exhibited skin rashes (table 1). After 8 months employment, case 2 developed thick keratotic plaques and fissures of the palms and soles, associated with dystrophic

Table 1. - Characteristics of popcorn plant cases, evaluated 1999-2001

\begin{tabular}{|c|c|c|c|c|c|c|c|c|c|}
\hline & \multicolumn{9}{|c|}{ Case no. } \\
\hline & 1 & 2 & 3 & 4 & 5 & 6 & 7 & 8 & 9 \\
\hline Age at symptom onset yrs & 39 & 51 & 41 & 27 & 33 & 44 & 42 & 34 & 48 \\
\hline Sex & M & M & $\mathrm{F}$ & M & M & $\mathrm{F}$ & $\mathrm{F}$ & $\mathrm{F}$ & M \\
\hline Smoking pack-yrs & 1 & 25 & 0 & 8 & 15 & 0 & 50 & 1.5 & 0 \\
\hline Mixing job & + & + & - & + & + & - & - & - & + \\
\hline Year employment started & 1984 & 1997 & 1993 & 1997 & 1990 & 1994 & 1996 & 1998 & 1992 \\
\hline Year of symptom onset & 1993 & 1998 & 1994 & 1998 & 1996 & 1995 & 1997 & 1998 & 1994 \\
\hline Year employment stopped & 2001 & 1999 & 1994 & 1999 & 1999 & 1996 & 1998 & 2000 & 1999 \\
\hline Acute onset & - & - & + & + & - & - & - & - & - \\
\hline Cough & + & + & + & + & + & + & + & + & + \\
\hline Dyspnoea & + & + & + & + & + & + & + & + & + \\
\hline Wheeze & + & + & + & + & + & + & + & + & + \\
\hline Phlegm & - & - & - & - & + & - & - & + & + \\
\hline Weight loss since symptom onset $\mathrm{kg}$ & 9.6 & 22.7 & 3.6 & 0 & 15.9 & 9.1 & 3.6 & 0 & 13.6 \\
\hline Fever & + & - & - & - & + & - & + & + & - \\
\hline Myalgia & + & + & + & + & + & + & + & + & + \\
\hline Fatigue & + & + & + & + & + & + & + & + & + \\
\hline Night sweats & + & - & + & + & - & + & + & + & - \\
\hline Eye irritation & + & + & + & + & + & + & + & + & + \\
\hline Nasal irritation & - & - & - & + & + & + & + & + & - \\
\hline Skin irritation & - & + & - & - & + & - & - & - & - \\
\hline Year listed for lung transplant & & & 1995 & 1999 & & 2000 & & & 1999 \\
\hline
\end{tabular}

M: male; F: female; +: present; -: absent. 
Table 2.-Pulmonary function test results of popcorn plant cases

Case no.

\begin{tabular}{lcccccccccc} 
& \multicolumn{10}{c}{ Case no. } \\
\cline { 2 - 9 } & 1 & 2 & 3 & 4 & 5 & 6 & 7 & 8 & 9 \\
\hline FEV1 \% pred & & & & & & & & & \\
$\quad$ First & 56.9 & 53.1 & 27.8 & 14.0 & 21.5 & 23.3 & 66.8 & 43.5 & 21.7 \\
$\quad$ Recent & 35.1 & 29.5 & 14.9 & 21.9 & 23.7 & 31.8 & 51.0 & 58.4 & 18.4 \\
FVC \% pred & & & & & & & & & \\
$\quad$ First & 71.6 & 67.8 & 59.7 & 22.5 & 48.6 & 41.6 & 63.1 & 70.3 & 45.6 \\
$\quad$ Recent & 59.3 & 56.5 & 56.2 & 48.2 & 49.8 & 72.4 & 70.9 & 71.3 & 61.3 \\
FEV1/FVC \% & & & & & & & & & \\
$\quad$ First & 63.2 & 60.9 & 37.9 & 51.3 & 35.8 & 44.5 & 86.1 & 50.4 & 37.8 \\
$\quad$ Recent & 46.2 & 40.2 & 21.1 & 37.0 & 38.2 & 34.6 & 57.9 & 67.4 & 23.3 \\
TLC \% pred & & & & & & & & & \\
$\quad$ First & 121 & & 110 & 83 & 94 & 103 & & 71 & 104 \\
$\quad$ Recent & 127 & & 107 & 120 & 112 & 126 & & 90 & 117 \\
RV \% pred & & & & & & & & & \\
$\quad$ First & 222 & & 193 & 188 & 214 & 209 & & 66 & 235 \\
$\quad$ Recent & 256 & & 207 & 347 & 295 & 245 & & 118 & 291 \\
RV/TLC \% & & & & & & & & & \\
$\quad$ First & 55 & & 56 & 56 & 56 & 69 & & 28 & 60 \\
$\quad$ Recent & 57 & & 66 & 64 & 61 & 70 & & 40 & 70 \\
$D$ L,CO \% pred & 99 & & 91 & 60 & 86 & 100 & & 61 & 81 \\
\hline
\end{tabular}

FEV1: forced expiratory volume in one second; FVC: forced vital capacity; TLC: total lung capacity; RV: residual volume; $D \mathrm{~L}, \mathrm{CO}$ : carbon monoxide diffusing capacity of the lung; $\%$ pred: percentage of the predicted value.
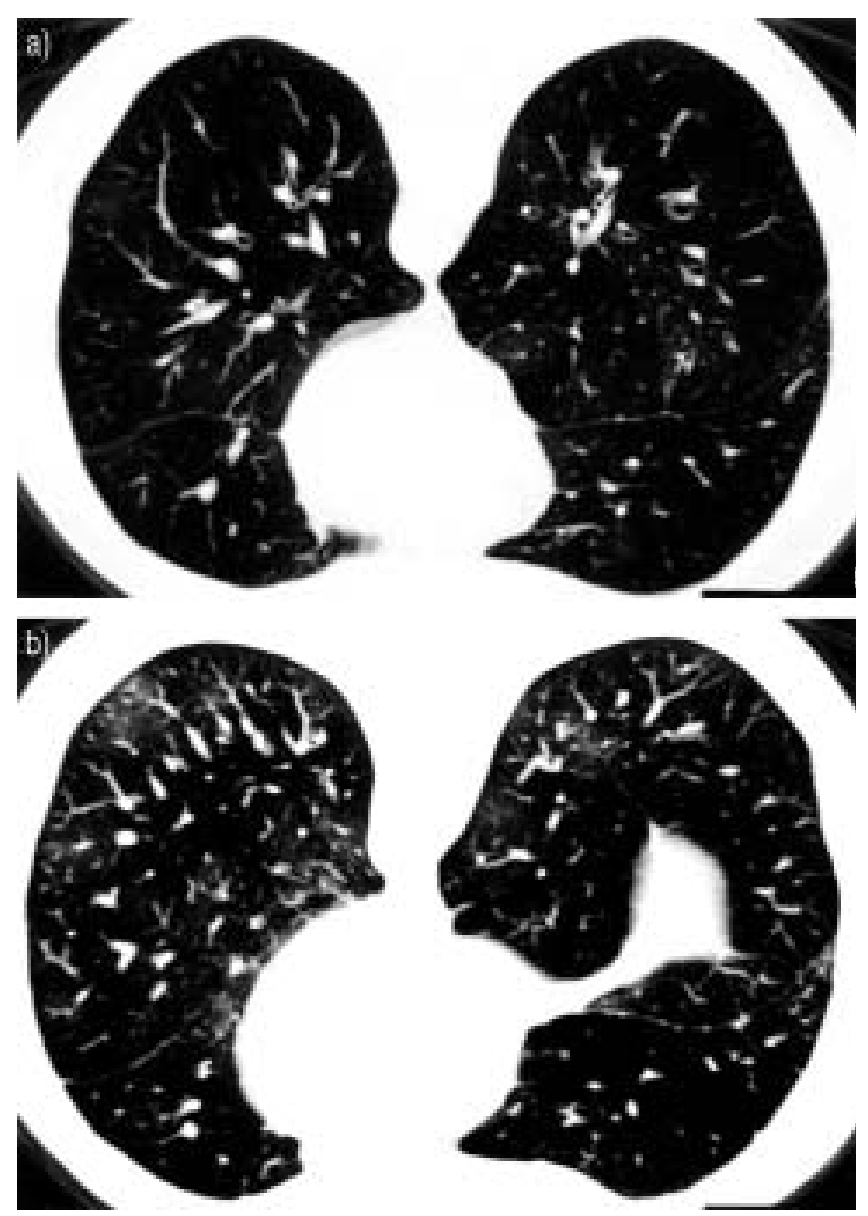

Fig. 2.-High-resolution computed tomography chest scans: a) inspiratory, showing mild heterogeneity of lung density, with cylindrical bronchiectasis in the right lower lobe; and b) expiratory, showing moderate patchy air trapping.

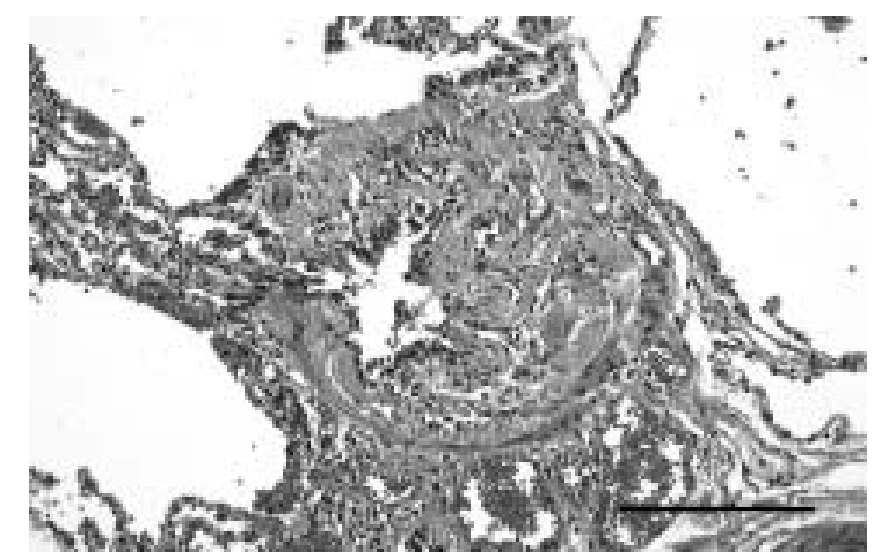

Fig. 3. - Thoracoscopic lung biopsy sample revealing constrictive bronchiolitis. The bronchiole shows marked submucosal fibrosis causing severe narrowing of the airway lumen. Scale bar=1 mm.

fingernails. Skin punch biopsy revealed mild acanthosis and spongiosis with focal superficial epidermal necrosis and an associated subepidermal dense lymphohistiocytic infiltrate. Patch testing showed early and late reactions to two butter flavourings and late reactions to six other butter flavourings, all used in the plant. His dermatitis improved when he stopped work.

Three cases underwent thoracoscopic lung biopsy. The biopsy sample from case 1 showed mild emphysema, rare granulomas, focal lesions of submucosal fibrosis and narrowing of the airway lumina (bronchioles) with mild chronic bronchiolitis and mucostasis, all of which supported the diagnosis of constrictive bronchiolitis (fig. 3). Case 3 had rare granulomas, with one section showing fibroblastic proliferation compromising the bronchiolar lumen consistent with bronchiolitis obliterans. Case 9 exhibited mild emphysema, unilateral pleural changes consistent with recurrent pneumothoraces and subpleural interstitial fibrosis probably related to the pneumothoraces.

None of the nine cases received an initial diagnosis of bronchiolitis obliterans syndrome. Diagnoses of pneumonia, asthma, emphysema, bronchitis, chronic obstructive pulmonary disease, hay fever and sinusitis were common. All cases were prescribed oral corticosteroids without showing improvement in airways obstruction. Two received cyclophosphamide treatment and reported symptomatic improvement, but no pulmonary function improvement was evident.

After leaving plant employment, cough intensity and frequency slowly decreased in seven of the nine cases. However, dyspnoea remained largely unchanged. Cases 2 and 7 showed considerable deterioration in symptoms and pulmonary function, even 16-28 months after leaving their work, but appear to have subsequently stabilised. The typical pattern of lung function impairment appears to be irreversible fixed airways obstruction. However, Case 8 showed substantial improvement in FEV1 after leaving employment. Five cases are on lung transplantation waiting lists, but to date exhibit stable physiology with annual follow up.

\section{Discussion}

The present cases were diagnosed over an 8-yr period among $\sim 450$ former workers, amongst whom lung disease of this severity and affecting so many would be markedly unusual [8]. The occurrence of four lung transplantation-listed patients in a sparsely populated rural area, with additional cases with 
similar physiological impairment, contributed to the recognition of a new occupational hazard.

Several observations were made supporting the occupational origin of this disease. The excess of disease was not uniformly distributed in the plant. Cases worked in the mixing room and microwave popcorn packaging area, and no cases occurred among the workers in remaining areas, such as kernel packaging, warehouse, outdoor and office areas. The present cases represent only a portion of the disease burden associated with this workforce. A systematic cross-sectional survey of current workers identified excess symptoms and excess obstructive abnormalities in relation to cumulative diacetyl exposure [6]. The clinical course of symptomatic improvement after leaving work was also consistent with an occupational aetiology.

Smoking history did not appear to contribute to this case cluster. Of the four cases on transplantation lists, three had never smoked and the fourth had a cumulative cigarette consumption of 8 pack-yrs. Of the six who had ever smoked, only one was in an age range in which smoking-related obstruction might be expected, and the remainder were in the age range $27-42$ yrs. The heaviest smoker (50 pack-yrs) showed the least FEV1 impairment on presentation. The $67.8 \%$ ever smokers among the sentinel cases was similar to the $55 \%$ in the cross-sectional survey of current workers in the plant [6], although cumulative cigarette consumption was trivial in half of the ever-smoking cases. In this sentinel case series, it cannot be determined whether smoking might exert a protective effect; in the cross-sectional study of current workers, smokers showed excess obstruction and chest symptoms, but to a lesser extent than never smokers.

The nine cases presented a spectrum of disease distinguished by severity. Although irreversible fixed airways obstruction typifies the lung transplantation-listed cases, others appear to have shown slow improvement of their fixed obstruction after leaving the plant. One of these cases exhibited mixed restrictive and obstructive disease and a low $D$ L, CO, consistent with bronchiolitis obliterans and organising pneumonia or hypersensitivity pneumonitis. Thus the exposure(s) in the plant may be associated with a spectrum of clinical and pathological entities, including constrictive bronchiolitis obliterans syndrome, proliferative bronchiolitis obliterans, hypersensitivity pneumonitis, interstitial fibrosis and mild emphysema [3,9]. The rare granulomas seen in two biopsy samples were not thought by the pathologist to be consistent with hypersensitivity pneumonitis, and their extent was insufficient to explain the patients' severe physiological impairment. Similarly, the mild emphysema documented on nondiagnostic biopsy in case 9, a never smoker, did not explain his status on a lung transplantation list. Pathological uncertainty remains, but the physiological and imaging features of these cases, fixed obstruction, largely normal chest radiographs, and bronchiectasis and air trapping on HRCT, were most consistent with bronchiolitis obliterans syndrome [3, 10]. The presence of myalgia, subjective fever and weight loss are not helpful in discriminating between the pathological entities considered. The pathophysiology remains elusive and may be best approached in animal models [11] and clinical investigation of any future cases with bronchoalveolar lavage studies.

Clinicians evaluating patients with unexplained cough, progressive exertional dyspnoea, and fixed airflow limitation, with or without restriction, should consider the diagnosis of bronchiolitis obliterans syndrome. The CT features seen in these cases are typical of bronchiolitis obliterans $[12,13]$. The primary CT feature of bronchiolitis obliterans on inspiratory HRCT is a mosaic pattern of lung attenuation. Expiratory imaging confirms the presence of diffuse or focal air trapping and may be abnormal even if inspiratory CT results are normal [14]. Mild cylindrical bronchiectasis is common. The presence of a tree-in-bud pattern should suggest the presence of a more active inflammatory bronchiolitis. Three cases in this series showed additional findings of irregular subpleural nodularity and mild volume loss, suggesting that there may be a mild degree of interstitial fibrosis present in some cases. Recognition of the typical HRCT features of bronchiolitis obliterans, as seen in this study, may obviate the need for biopsy in those with occupational exposure to a recognised agent. The $\mathrm{CT}$ features of this new work-related condition are clearly distinct from those of flock worker's lung, which is characterised by ground-glass abnormality and evidence of lung fibrosis [15]. The imaging features are also distinct from the features of hypersensitivity pneumonitis, which is characterised by poorly defined centrilobular nodules and ground-glass abnormality [16].

Open or thoracoscopic lung biopsy is critical to obtaining adequate tissue for evaluation of the lung, and the tissue blocks may require serial sectioning to reveal bronchiolar architecture. Sometimes, even in expert hands, the tissue samples obtained may be small, fragmented and distorted, thus rendering assessment of lung architecture difficult. In the pathological examination of case 1 , tissue changes supporting a diagnosis of constrictive bronchiolitis were observed; biopsy samples from two other cases were not diagnostic of bronchiolitis. However, these patients showed severe obstructive pulmonary defects and mosaic patterns on HRCT, and the negative biopsy results were probably due to a recognised sampling problem. The patchy distribution of the disease can result in sampling error, with false negative results [17]. A cell-mediated immune mechanism may have occurred in case 2 , who exhibited allergic contact dermatitis and delayed-type hypersensitivity to butter flavourings on patch testing, as well as severe fixed airflow limitation. However, the absence of an objective response in the cases that were treated with a corticosteroid trial within months of becoming symptomatic seems inconsistent with cell-mediated immunological airway damage alone.

Biopsy-confirmed bronchiolitis obliterans cases among workers at two flavouring manufacturing companies and a company packaging flavourings for the baking industry have been reported to NIOSH $[18,19]$. NIOSH has also received a case report of biopsy-confirmed bronchiolitis obliterans organising pneumonia in snack food manufacturing workers using flavourings or spices [20]. In addition, a case of fixed airways obstruction occurred in another microwave popcorn plant [21]. These reports confirm the potential lung hazards of flavouring manufacture and use in industrial food preparation. There may be similar reactive chemicals causing chronic obstructive airways disease in other industries.

Clinicians should be alert to this syndrome. Cases of unexplained fixed airways obstruction should be brought to the attention of public health authorities in order to permit follow-up epidemiological investigations. These may help extend knowledge to previously unrecognised causes of chronic obstructive lung diseases and lead to effective intervention to prevent additional cases.

Acknowledgements. The authors thank the cases for permission to share their medical information; A. Hubbs (National Institute for Occupational Safety and Health (NIOSH), Morgantown, WV, USA) and T. Colby (Mayo Clinic, Scottsdale, AZ, USA) for reviewing pathology slides; and A. Gomaa (NIOSH), P. Enright (NIOSH) and G. Caplan (Rocky Mountain Center for Occupational and Environmental Medicine, Salt Lake City, UT, USA) for early compilations of clinical data. 


\section{References}

1. King TE Jr. Bronchiolitis. In: Schwarz MI, King TE Jr, eds. Interstitial Lung Disease. 3rd Edn. Hamilton-London, B.C. Decker, Inc., 1998; pp. 645-684.

2. Boswell RT, McCunney RJ. Bronchiolitis obliterans from exposure to incinerator fly ash. J Occup Environ Med 1995; 37: 850-855.

3. King TE Jr. Bronchiolitis obliterans. Lung 1989; 167: 69-93.

4. Simpson FG, Belfield PW, Cooke NJ. Chronic airflow limitation after inhalation of overheated cooking oil fumes. Postgrad Med J 1985; 61: 1001-1002.

5. Spain BA, Cummings O, Garcia JG. Bronchiolitis obliterans in an animal feed worker. Am J Ind Med 1995; 28: 437-443.

6. Kreiss K, Gomaa A, Kullman G, Fedan K, Simes EJ, Enright PL. Clinical bronchiolitis obliterans in workers at a microwave-popcorn plant. N Engl J Med 2002; 347: 330-361.

7. Hankinson JL, Odencrantz JR, Fedan KB. Spirometric reference values from a sample of the general U.S. population. Am J Respir Crit Care Med 1999; 159: 179-187.

8. Simoes E, Maley R, Kreiss K, Malone J, Kanwal R. Fixed obstructive lung disease in workers at a microwave popcorn factory: Missouri, 2000-2002. MMWR Recomm Rep 2002; 51: 354-357.

9. Mormile F, Ciappi G. Airway disease: anatomopathologic patterns and functional correlations. Rays 1997; 22: 107-126.

10. Worthy SA, Muller NL. Small airway diseases. Radiol Clin North Am 1998; 36: 163-173.

11. Hubbs AF, Battelli LA, Goldsmith WT, et al. Necrosis of nasal and airway epithelium in rats inhaling vapors of artificial butter flavoring. Toxicol Appl Pharmacol 2002; 185: $128-135$.

12. Garg K, Lynch DA, Newell JD, King TE Jr. Proliferative and constrictive bronchiolitis: classification and radiologic features. AJR Am J Roentgenol 1994; 162: 803-808.
13. Padley SP, Adler BD, Hansell DM, Muller NL. Bronchiolitis obliterans: high resolution CT findings and correlation with pulmonary function tests. Clin Radiol 1993; 47: 236-240.

14. Arakawa H, Webb WR. Air trapping on expiratory highresolution CT scans in the absence of inspiratory scan abnormalities: correlation with pulmonary function tests and differential diagnosis. AJR Am J Roentgenol 1998; 170: $1349-1353$

15. Weiland DA, Lynch DA, Jensen SP, et al. Thin-section CT findings in flock worker's lung, a work-related interstitial lung disease. Radiology 2003; 227: 222-231.

16. Buschman DL, Gamsu G, Waldron JA Jr, Klein JS, King TE Jr. Chronic hypersensitivity pneumonitis: use of CT in diagnosis. AJR Am J Roentgenol 1992; 159: 957-960.

17. Flowers JR, Clunie G, Burke M, Constant O. Bronchiolitis obliterans organizing pneumonia: the clinical and radiological features of seven cases and a review of the literature. Clin Radiol 1992; 45: 371-377.

18. NIOSH (1986). Hazard evaluation and technical assistance report: International Bakers Services, South Bend, IN Cincinnati, OH. US Department of Health and Human Services, Public Health Service, Center for Disease Control, National Institute for Occupational Safety and Health, NIOSH Report No: HETA NIOSH HETA 85-171-1710.

19. Lockey J, Mckay R, Barth E, Dahlsten J, Baughman R. Bronchiolitis obliterans in the food flavoring manufacturing industry. Am J Respir Crit Care Med 2002; 165 A461.

20. Alleman T, Darcey DJ. Case report: bronchiolitis obliterans organizing pneumonia in a spice process technician. $J$ Occup Environ Med 2002; 44: 215-216.

21. Parmet AJ, Von Essen S. Rapidly progressive, fixed airway obstructive disease in popcorn workers: a new occupational pulmonary illness? J Occup Environ Med 2002; 44 216-218. 